\title{
Performance Comparison of a Typical Nonlinear Load Connected to ac and dc Power Grids
}

\author{
Tiago J. C. Sousa ${ }^{1}$, Vítor Monteiro ${ }^{1}, J^{\prime}$ G. Pinto ${ }^{1}$ and João L. Afonso ${ }^{1}$ \\ ${ }^{1}$ Centro ALGORITMI, University of Minho, Campus de Azurém, Guimarães, Portugal \\ tsousa@dei.uminho.pt
}

\begin{abstract}
This paper presents a performance comparison of a typical nonlinear load used in domestic appliances (electronic load), when supplied by an ac and a dc voltage of the same rms value. The performance of the nonlinear load towards its connection to ac and dc power grids is accomplished in terms of the waveforms which are registered in the consumed current, internal dc-link voltage and output voltage. A simulation model was developed using realistic database models of the power semiconductors comprising a nonlinear load with input ac-dc converter, so that the efficiency can be calculated and compared for three distinct cases: (1) load supplied by an ac voltage; (2) load supplied by a dc voltage; (3) load without the input ac-dc converter supplied by a dc voltage. Thus, besides the comparison between the ac and dc power grids supplying the same nonlinear load (cases 1 and 2), a third case is considered, which consists of removing the input ac-dc converter (eliminating needless components of the nonlinear load when supplied by a dc voltage). The obtained results show that supplying nonlinear loads with dc power grids is advantageous in relation to the ac power grid, and therefore it can be beneficial to adapt nonlinear loads to be powered by dc power grids.
\end{abstract}

Keywords: dc Grids, dc Smart Homes, Nonlinear Loads, Efficiency.

\section{Introduction}

Dc power transmission and dc grids have gained attention over the past few years. In the last century, ac power transmission was preferred due to transformers, which allow the changing of voltage and current levels in a reliable and efficient manner. Despite being heavy and bulky, transformers were a more suitable solution than power electronics-based converters towards the advent of power transmission, more than one hundred years ago. However, power electronics has been undergoing a significant development since the second half of the last century. This led to the establishment of the high voltage dc (HVDC) transmission systems, which was not only a research target at that time [1]-[9], but with real applications in the recent years [10]-[17]. In HVDC transmission systems, skin effect and voltage drops due to the conductors' reactance are inexistent when compared to ac power transmission. Moreover, HVDC power transmission can reduce power transmission losses even further with the appliance of superconductivity [18]-[24]. 
Besides the advent of HVDC transmission systems, the development of power electronics contributed to the implementation of more efficient and lower power demanding electrical loads. These loads are named nonlinear loads, i.e., the relation between the supplied voltage and the consumed current is not linear. This phenomenon gave rise to the widely known harmonic currents issue [25]-[29], as well as the respective proposed compensation techniques [30]-[34].

From the power grid point of view, nonlinear loads are comprised by a diode full-bridge ac-dc converter in the input, therefore operating in dc power at the output. In fact, this type of connection is present in the vast majority of domestic appliances, such as computers, televisions, modern refrigerators and modern lighting equipment such as compact fluorescent and light emitting diode (LED) lamps. Accordingly, the operation of nonlinear loads, both from the power grid and from the load point of view, can be improved if the traditional ac voltage supply is replaced by a dc voltage supply with equivalent rms value. Besides the electrical loads, the paradigm of dc grids is also more suitable than ac grids, which is proved by the dc systems based on photovoltaics, fuel cells and batteries. Dc microgrids are also an attractive asset for future power systems [35], [36] and can also be used for wind and wave power generation [37]. With the dc approach, power conversions can be reduced and the efficiency can be improved, whereby dc smart homes represent a viable alternative in the near future [38]-[41].

In this context, this paper presents a study about the performance of a typical nonlinear load connected to ac and dc power grids. The differences between the two types of power grids are analyzed in terms of consumed current, dc-link voltage and output voltage. A comparison is also made in terms of efficiency and a third case is considered, aiming to improve the efficiency of the type of nonlinear load under study in dc power grids. The analyses are based on simulation results using realistic database models of the power semiconductors comprising the load.

The paper is structured as follows: Section 2 presents the nonlinear load under analysis; Section 3 presents the developed simulation model and the obtained results in terms of waveforms and efficiency comparison. Section 4 finalizes the paper with the conclusions.

\section{Load Analysis: Electrical Model}

This section presents the electrical model of the load under analysis in this paper. As aforementioned, the typical loads used in domestic appliances are nonlinear loads. These loads are mainly comprised by an ac-dc converter, typically a diode full-bridge ac-dc converter with a filter capacitor, which converts the input ac voltage into an unregulated dc voltage. A dc-dc converter is connected downstream the filter capacitor in order to adjust the rectified voltage to the desired value, as well as to minimize its ripple. This load is basically a power supply that can be found in computers, televisions, modern refrigerators and battery chargers, for instance. Fig. 1 depicts this type of load, where the aforementioned elements can be seen. The ac-dc converter is comprised by diodes $D_{1}$ to $D_{4}$ and contains a filter capacitor $\left(C_{d c}\right)$ in order to smooth the dc-link voltage $\left(v_{d c}\right)$ and an input inductive filter $\left(L_{g}\right)$ in order to smooth the absorbed grid current 
$\left(i_{g}\right)$. The dc-dc converter $\left(S_{1}, D_{5}, L_{o}\right.$ and $\left.C_{o}\right)$ is a buck converter, whose function is to step-down the dc-link voltage $\left(v_{d c}\right)$ into a controlled output voltage $\left(v_{o}\right)$ with low ripple. Additionally, a resistor is connected in the output $\left(R_{o}\right)$ to emulate the power consumption of the load.

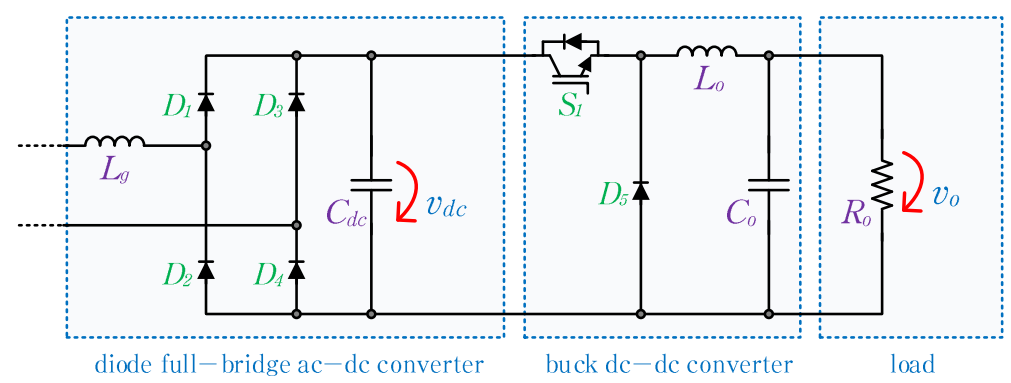

Fig. 1. Nonlinear load under analysis.

\section{$3 \quad$ Simulation Model and Results}

This section presents the simulation model developed in the software PSIM v9.1 and the subsequent performed analysis for the nonlinear load described in the previous section when fed by ac and dc power. Three different cases are considered: (1) load supplied by an ac voltage (Fig. 2 (a)); (2) load supplied by a dc voltage (Fig. 2 (b)); (3) load without the input ac-dc converter supplied by a dc voltage (Fig. 2 (c)). Case 1 represents the traditional connection of the considered nonlinear load to an ac power grid. Case 2 represents the same load connected to a dc power grid instead, meaning the case of a traditional nonlinear load connected in a possible dc home that can also be connected in a regular ac power grid. On the other hand, case 3 represents a possible evolution suffered by the considered type of load, being possible to discard the diode full-bridge ac-dc converter since both the input and the output are dc. However, this type of load can operate only in a dc power grid, whereby this scenario is only feasible when dc smart homes and dc grids would be widespread. Furthermore, case 3 is more prone to failure, as the input terminals of the load are polarized; an input voltage with a reverse polarity cannot supply the load properly and even can destroy the electronic components, while a diode full-bridge ac-dc converter assures a fixed polarity in the dc-link voltage.

The parameters considered in the simulation model for the ac and dc power grids and the loads are listed in Table 1. It should be mentioned that the value of $24 \mathrm{~V}$ used in the ac power grid refers to the secondary side of a $230 \mathrm{~V} / 24 \mathrm{~V}$ transformer, typically included in this type of loads, whereby the transformer is excluded from the analysis in order to compare the same load being supplied with ac and dc power. 


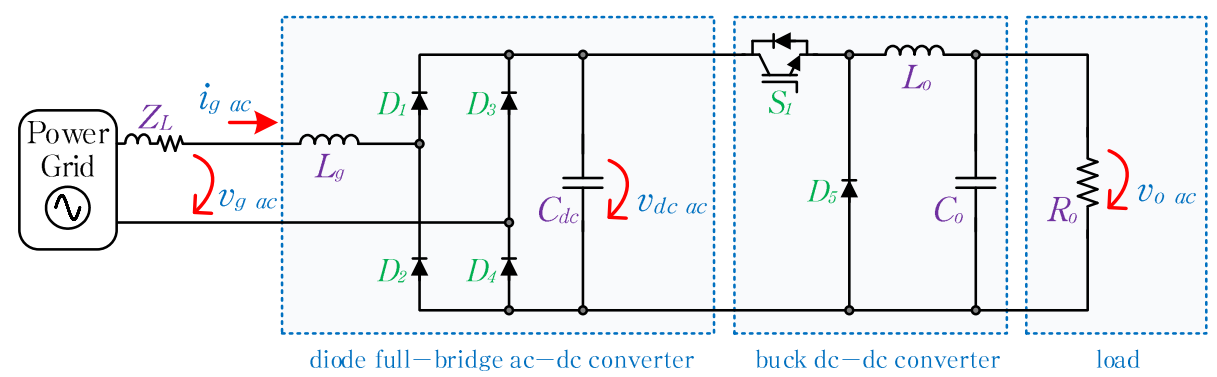

(a)

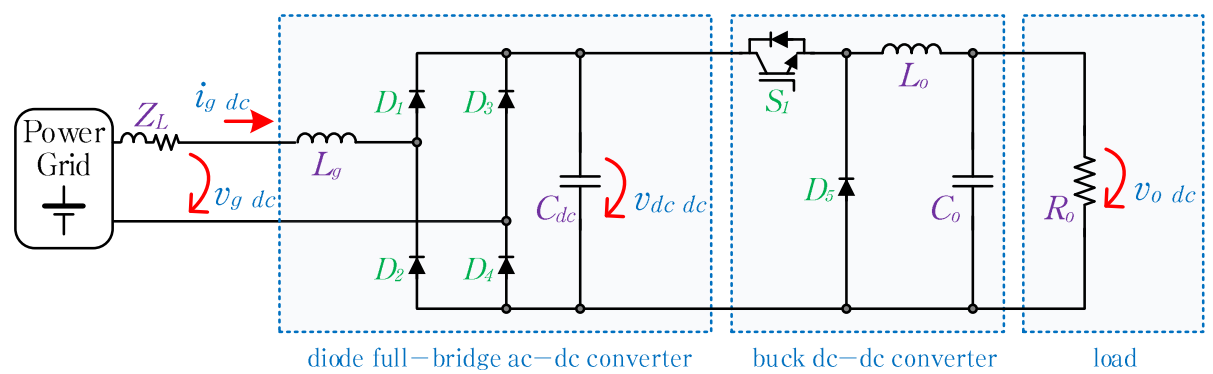

(b)

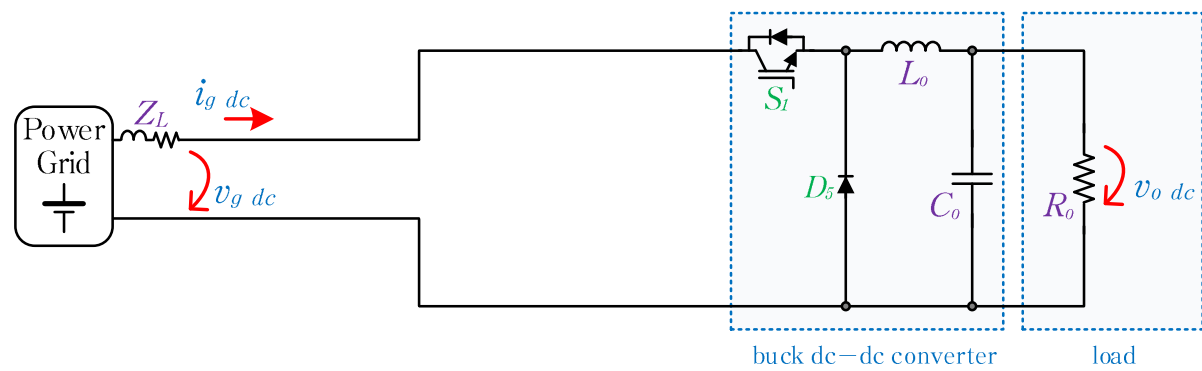

(c)

Fig. 2. Considered cases for the analyzed nonlinear load: (a) Load supplied by an ac voltage; (b) Load supplied by a dc voltage; (c) Load without the input ac-dc converter supplied by a dc voltage.

In order to perform an efficiency evaluation for the three cases, realistic database models of diodes and MOSFETs were used. The diodes used in both ac-dc and dc-dc converters are ST Microelectronics STTA206S (600 V, 8 A), and the MOSFET used in the dc-dc converter is International Rectifier IRF1010EZ (60 V, 75 A) switched at $20 \mathrm{kHz}$. It should be referred that the focus of analysis is the efficiency comparison between the cases and not the efficiency values per se. 
Table 1. System parameters of the developed simulation model.

\begin{tabular}{ll}
\hline Parameter & Value \\
\hline Ac Power Grid $\left(v_{g_{-} a c}\right)$ & $24 \mathrm{~V}, 50 \mathrm{~Hz}$ \\
Dc Power Grid $\left(v_{g_{-} d c}\right)$ & $24 \mathrm{~V}$ \\
Output Voltage $\left(v_{o}\right)$ & $12 \mathrm{~V}$ \\
Line Impedance $\left(\mathrm{Z}_{L}\right)$ & $1 \mathrm{~m} \Omega, 50 \mu \mathrm{H}$ \\
Input Inductor $\left(L_{g}\right)$ & $1 \mathrm{mH}$ \\
Dc-link Capacitor $\left(C_{d c}\right)$ & $1 \mathrm{mF}$ \\
Output Inductor $\left(L_{o}\right)$ & $2 \mathrm{mH}$ \\
Output Capacitor $\left(C_{o}\right)$ & $470 \mu \mathrm{F}$ \\
Output Resistor $\left(R_{o}\right)$ & $10 \Omega$ \\
\hline
\end{tabular}

\subsection{Waveform Comparison}

This section compares the waveforms of the main voltage and current quantities of the system comprised by the power grid and the load. In this analysis, only case 1 and 2 are scrutinized so that a comparison of ac and dc voltage supply with the same rms value for the same connected load is performed.

The waveforms of the current consumed by the nonlinear load from the power grid point of view can be seen in Fig. 3, where $i_{g_{\_} a c}$ relates to the ac power grid and $i_{g_{-} d c}$ to the dc power grid. As expected, the current consumed by this type of load presents a distorted waveform when supplied by an ac voltage, while presenting a constant value when supplied by a dc voltage. Besides the difference in the waveforms, the current rms values also differ for the same rms supply voltage, being $1.1 \mathrm{~A}$ and $0.75 \mathrm{~A}$ for ac and dc voltage, respectively. This can be explained by the consumption of reactive power in the ac case, which in dc does not exist.

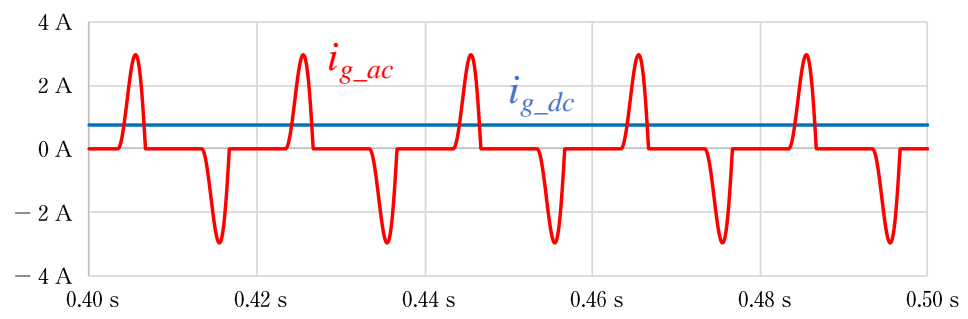

Fig. 3. Current consumed by the load when supplied by ac voltage $\left(i_{g_{-} a c}\right)$ and when supplied by dc voltage $\left(i_{g_{-}} d c\right)$.

Besides the differences in the grid current, the connection of this type of load to ac or dc power grids also results in differences in the dc-link voltage, i.e., the voltage rectified by the diode full-bridge ac-dc converter and the input voltage of the buck dc-dc 
converter. Fig. 4 shows the waveforms of the dc-link voltage for the same load when supplied by an ac power grid $\left(v_{d c_{-} a c}\right)$ and when supplied by a dc power grid $\left(v_{d c_{-} d c}\right)$. As expected, the dc-link voltage in the ac power grid case exhibits a double grid frequency ripple $(100 \mathrm{~Hz})$ resultant from the ac-dc power conversion, while the ripple in the dc power grid case is negligible. Besides, the average value of the dc-link voltage is higher in the first case $(29.5 \mathrm{~V})$ because the $24 \mathrm{~V}$ rms sinusoidal voltage has a peak value of $34 \mathrm{~V}$. Nevertheless, in the ac case occurs a voltage drop in the load input inductor $\left(L_{g}\right)$, which is inexistent in dc. The average value of the dc-link voltage in the dc case is $20.9 \mathrm{~V}$, with the diodes voltage drop being the main source of voltage decrease with respect to the power grid voltage.

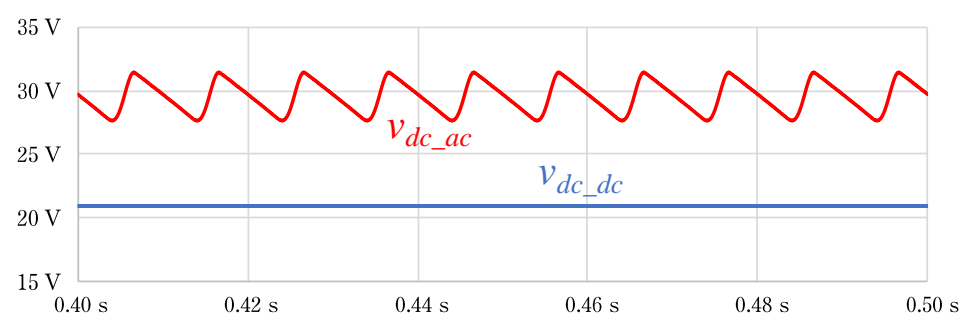

Fig. 4. Dc-link voltage of the load when supplied by ac voltage $\left(v_{d c_{-} a c}\right)$ and when supplied by dc voltage $\left(v_{d c \_d c}\right)$.

Fig. 5 shows the waveforms of the output voltage of the load for the ac case $\left(v_{o_{a} a c}\right)$ and the dc case $\left(v_{o_{-} d c}\right)$. The buck dc-dc converter is responsible for the synthetization of this voltage, in both cases controlling its value to $12 \mathrm{~V}$. Although the ripple is small in both cases, it is even smaller in the dc case, since the constant dc-link voltage facilitates the control of the output voltage. Consequently, the ripple component of the output voltage in the dc case consists of switching ripple only. It should be noted that the same control strategy was applied in both cases.

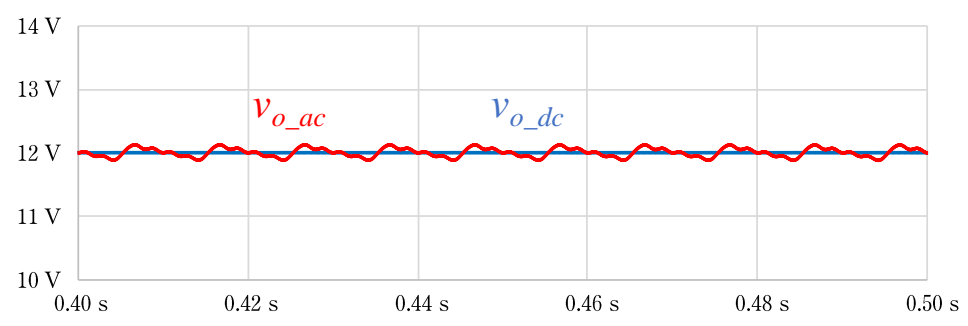

Fig. 5. Output voltage of the load when supplied

by ac voltage $\left(v_{o_{-} a c}\right)$ and when supplied by dc voltage $\left(v_{o_{-}} d c\right)$.

\subsection{Efficiency Comparison}

The previous results compared the voltage and current waveforms of the power grid and the load for the same load being supplied with ac and dc voltages. In this section, 
case 3 (load without input ac-dc converter supplied by a dc voltage) is also analyzed and compared with the other two cases in terms of efficiency.

Table 2 presents a comparison in terms of input power, output power and efficiency for the three designed cases. Since the load output voltage is the same for the three cases $(12 \mathrm{~V})$, as well as the output resistor $(10 \Omega)$, the output power is $14.4 \mathrm{~W}$ for all the cases. In terms of input active power, i.e., the active power absorbed from the power grid, it should be noted that case 1 presents a lower value than case $2(17.9 \mathrm{~W}$ against $18.1 \mathrm{~W}$ ) and, consequently, a higher efficiency $(80.4 \%$ against $79.6 \%)$. This is justified by the fact that the power losses in the diodes of the ac-dc converter are $1.92 \mathrm{~W}$ in case 1 and $2.32 \mathrm{~W}$ in case 2 . However, in case 1 there is an apparent power of $26.7 \mathrm{VA}$, corresponding to a power factor of 0.67 , which does not exist in cases 2 and 3 , since these are related to dc grids. Nonetheless, the highest efficiency is attained by removing the ac-dc converter (case 3), resulting in a $96 \%$ efficiency for the same load supplied by a de power grid.

Table 2. Power and efficiency comparison for the three cases.

\begin{tabular}{cccc}
\hline Case & $\begin{array}{c}\text { 1 (ac grid with } \\
\text { ac-dc converter) }\end{array}$ & $\begin{array}{c}\text { 2 (dc grid with } \\
\text { ac-dc converter) }\end{array}$ & $\begin{array}{c}3 \text { (dc grid without } \\
\text { ac-dc converter) }\end{array}$ \\
\hline Input Active Power & $17.9 \mathrm{~W}$ & $18.1 \mathrm{~W}$ & $15.0 \mathrm{~W}$ \\
Output Active Power & $14.4 \mathrm{~W}$ & $14.4 \mathrm{~W}$ & $14.4 \mathrm{~W}$ \\
Efficiency & $80.4 \%$ & $79.6 \%$ & $96.0 \%$ \\
\hline
\end{tabular}

\section{Conclusions}

This paper presented an analysis of a typical nonlinear load used in domestic appliances and its behavior when connected to an ac power grid and to a dc power grid, both with the same rms voltage value. The considered load was a diode full-bridge ac-dc converter followed by a buck dc-dc converter, representing a typical power supply that can be found in computers, phone battery chargers, among other domestic appliances. Three distinct cases were considered, namely: (1) load supplied by an ac voltage; (2) load supplied by a dc voltage; (3) load without the input ac-dc converter supplied by a dc voltage. A simulation model was developed considering realistic database models of the power semiconductors used in this type of load, i.e., diodes and an MOSFET. The attained simulation results aimed to perform a comparison in terms of waveforms and efficiency, which was feasible due to the database model of the power semiconductors. It was seen that efficiency can be significantly improved (from $80 \%$ to $96 \%$ ) in a dc power grid by simply removing the input ac-dc converter of the analyzed type of nonlinear load. This fact corroborates the feasibility of dc smart homes and dc grids, making them more suitable, not only from the renewable energy generation and from energy storage systems point of view, but also from the perspective of the vast majority of electrical appliances. 


\section{Acknowledgments}

This work has been supported by COMPETE: POCI-01-0145-FEDER-007043 and FCT - Fundação para a Ciência e Tecnologia within the Project Scope: UID/CEC/00319/2013. This work is financed by the ERDF - European Regional Development Fund through the Operational Programme for Competitiveness and Internationalisation - COMPETE 2020 Programme, and by National Funds through the Portuguese funding agency, FCT - Fundação para a Ciência e a Tecnologia, within project SAICTPAC/0004/2015 - POCI - 01-0145-FEDER-016434. Mr. Tiago Sousa is supported by the doctoral scholarship SFRH/BD/134353/2017 granted by the Portuguese FCT agency.

\section{References}

1. R. Foerst, G. Heyner, K. Kanngiesser, and H. Waldmann, "Multiterminal Operation of HVDC Converter Stations," IEEE Transactions on Power Apparatus and Systems, vol. PAS88, no. 7, pp. 1042-1052, Jul. 1969.

2. C. Dewey, F. Ellert, T. Lee, and C. TITUS, "Development of Experimental 20-kY, 36-MW Solid-State Converters for HVDC Systems," IEEE Transactions on Power Apparatus and Systems, vol. PAS-87, no. 4, pp. 1058-1066, Apr. 1968.

3. F. Hirsch and E. Schafer, "Progress Report on the HVDC Test Line of the $400 \mathrm{kV}$-Forschungsgemeinschaft: Corona Losses and Radio Interference," IEEE Transactions on Power Apparatus and Systems, vol. PAS-88, no. 7, pp. 1061-1069, Jul. 1969.

4. N. Hingorani, "Transient Overvoltage on a Bipolar HVDC Overhead Line Caused by DC Line Faults," IEEE Transactions on Power Apparatus and Systems, vol. PAS-89, no. 4, pp. 592-610, Apr. 1970.

5. J. Reeve, J. Baron, and P. Krishnayya, “A General Approach to Harmonic Current Generation by HVDC Converters," IEEE Transactions on Power Apparatus and Systems, vol. PAS88, no. 7, pp. 989-995, Jul. 1969.

6. J. S. Hess and L. R. Rice, "Three Megawatt HVDC Transmission Simulator," IEEE Transactions on Industry and General Applications, vol. IGA-3, no. 6, pp. 531-537, Nov. 1967.

7. A. Ekstrom and G. Liss, "A Refined HVDC Control System," IEEE Transactions on Power Apparatus and Systems, vol. PAS-89, no. 5, pp. 723-732, May 1970.

8. T. Horigome, K. Kurokawa, K. Kishi, and K. Ozu, "A 100-kV thyristor converter for highvoltage dc transmission," IEEE Transactions on Electron Devices, vol. 17, no. 9, pp. 809815, Sep. 1970.

9. C. Heising and R. Ringlee, "Prediction of Reliability and Availability of HVDC Valve and HVDC Terminal," IEEE Transactions on Power Apparatus and Systems, vol. PAS-89, no. 4, pp. 619-624, Apr. 1970.

10. N. G. Hingorani, "High-voltage DC transmission: a power electronics workhorse," IEEE Spectrum, vol. 33, no. 4, pp. 63-72, Apr. 1996.

11. T. J. Hammons et al., "Role of HVDC transmission in future energy development," IEEE Power Engineering Review, vol. 20, no. 2, pp. 10-25, Feb. 2000.

12. N. A. Belda, C. A. Plet, and R. P. P. Smeets, "Analysis of Faults in Multiterminal HVDC Grid for Definition of Test Requirements of HVDC Circuit Breakers," IEEE Transactions on Power Delivery, vol. 33, no. 1, pp. 403-411, Feb. 2018. 
13. N. Flourentzou, V. G. Agelidis, and G. D. Demetriades, "VSC-Based HVDC Power Transmission Systems: An Overview," IEEE Transactions on Power Electronics, vol. 24, no. 3, pp. 592-602, Mar. 2009.

14. C. M. Franck, "HVDC Circuit Breakers: A Review Identifying Future Research Needs," IEEE Transactions on Power Delivery, vol. 26, no. 2, pp. 998-1007, Apr. 2011.

15. C. Guo, Y. Zhang, A. M. Gole, and C. Zhao, "Analysis of Dual-Infeed HVDC With LCCHVDC and VSC-HVDC," IEEE Transactions on Power Delivery, vol. 27, no. 3, pp. 15291537, Jul. 2012.

16. G. Liu, F. Xu, Z. Xu, Z. Zhang, and G. Tang, "Assembly HVDC Breaker for HVDC Grids With Modular Multilevel Converters," IEEE Transactions on Power Electronics, vol. 32, no. 2, pp. 931-941, Feb. 2017.

17. Y. Liu and Z. Chen, "A Flexible Power Control Method of VSC-HVDC Link for the Enhancement of Effective Short-Circuit Ratio in a Hybrid Multi-Infeed HVDC System," IEEE Transactions on Power Systems, vol. 28, no. 2, pp. 1568-1581, May 2013.

18. S.-M. Baek, H.-J. Kim, J.-W. Cho, and H.-S. Ryoo, "Cryogenic Electrical Insulation Characteristics of Solid Insulator for the HVDC HTS Cable," IEEE Transactions on Applied Superconductivity, vol. 28, no. 4, pp. 1-4, Jun. 2018.

19. Taesik Nam, Jae Woong Shim, and Kyeon Hur, "Design and Operation of Double SMES Coils for Variable Power System Through VSC-HVDC Connections," IEEE Transactions on Applied Superconductivity, vol. 23, no. 3, pp. 5701004-5701004, Jun. 2013.

20. J. G. Kim et al., "Loss characteristic analysis of HTS DC power cable using LCC based DC transmission system," IEEE Transactions on Applied Superconductivity, vol. 22, no. 3, pp. 3-6, 2012.

21. B. Malek and B. K. Johnson, "Branch Current Control on a Superconducting DC Grid," IEEE Transactions on Applied Superconductivity, vol. 23, no. 3, pp. 5401005-5401005, Jun. 2013

22. Q. Yang, S. Le Blond, F. Liang, W. Yuan, M. Zhang, and J. Li, "Design and Application of Superconducting Fault Current Limiter in a Multiterminal HVDC System," IEEE Transactions on Applied Superconductivity, vol. 27, no. 4, pp. 1-5, Jun. 2017.

23. Bin Xiang, Zhiyuan Liu, Yingsan Geng, and S. Yanabu, "DC Circuit Breaker Using Superconductor for Current Limiting," IEEE Transactions on Applied Superconductivity, vol. 25, no. 2, pp. 1-7, Apr. 2015.

24. A. Marian, S. Holé, F. Lesur, M. Tropeano, and C. E. Bruzek, "Validation of the superconducting and insulating components of a high-power HVDC cable," IEEE Electrical Insulation Magazine, vol. 34, no. 1, pp. 26-36, Jan. 2018.

25. IEEE Standards Association, "IEEE Recommended Practice and Requirements for Harmonic Control in Electric Power Systems," in IEEE Std 519-2014 (Revision of IEEE Std 519-1992), vol. 2014, pp. 1-29, 2014.

26. J. H. R. Enslin and P. J. M. Heskes, "Harmonic Interaction Between a Large Number of Distributed Power Inverters and the Distribution Network," IEEE Transactions on Power Electronics, vol. 19, no. 6, pp. 1586-1593, Nov. 2004.

27. W. K. A. Gonçalves, J. C. De Oliveira, and V. L. S. Franco, "Harmonics Produced by Advanced Static Var Compensator under Electric Power Supply Conditions with Loss of Quality," International Conference on Electric Utility Deregulation and Restructuring and Power Technologies Proceedings, pp. 660-665, 2000.

28. A. M. Blanco, R. Stiegler, and J. Meyer, "Power quality disturbances caused by modern lighting equipment (CFL and LED)," in 2013 IEEE Grenoble Conference, 2013, pp. 1-6.

29. R. C. Dugan, M. F. McGranaghan, S. Santoso, and H. W. Beaty, Electrical Power Systems Quality, 3rd Editio. 2004. 
30. W. M. Grady, M. J. Samotyj, and A. H. Noyola, "Survey of active power line conditioning methodologies," IEEE Transactions on Power Delivery, vol. 5, no. 3, pp. 1536-1542, Jul. 1990.

31. G. A. Taylor, "Power quality hardware solutions for distribution systems: Custom Power," in IEE North Eastern Centre Power Section Symposium on the Reliability, Security and Power Quality of Distribution Systems, 1995, vol. 1995, pp. 1-9.

32. B. Singh, K. Al-Haddad, and A. Chandra, "A review of active filters for power quality improvement," IEEE Transactions on Industrial Electronics, vol. 46, no. 5, pp. 960-971, 1999.

33. M. M. Morcos and J. C. Gomez, "Electric power quality - the strong connection with power electronics," IEEE Power and Energy Magazine, vol. 1, no. 5, pp. 18-25, 2003.

34. V. Khadkikar, "Enhancing Electric Power Quality Using UPQC: A Comprehensive Overview," IEEE Transactions on Power Electronics, vol. 27, no. 5, pp. 2284-2297, May 2012.

35. T. Dragicevic, J. C. Vasquez, J. M. Guerrero, and D. Skrlec, "Advanced LVDC Electrical Power Architectures and Microgrids: A step toward a new generation of power distribution networks.," IEEE Electrification Magazine, vol. 2, no. 1, pp. 54-65, Mar. 2014.

36. A. Kwasinski, "Quantitative Evaluation of DC Microgrids Availability: Effects of System Architecture and Converter Topology Design Choices," IEEE Transactions on Power Electronics, vol. 26, no. 3, pp. 835-851, Mar. 2011.

37. S. Lu, L. Wang, T.-M. Lo, and A. V. Prokhorov, "Integration of Wind Power and Wave Power Generation Systems Using a DC Microgrid," IEEE Transactions on Industry Applications, vol. 51, no. 4, pp. 2753-2761, Jul. 2015.

38. B. T. Patterson, "DC, Come Home: DC Microgrids and the Birth of the 'Enernet," IEEE Power and Energy Magazine, vol. 10, no. 6, pp. 60-69, 2012.

39. E. Rodriguez-Diaz, J. C. Vasquez, and J. M. Guerrero, "Intelligent DC Homes in Future Sustainable Energy Systems: When efficiency and intelligence work together," IEEE Consumer Electronics Magazine, vol. 5, no. 1, pp. 74-80, Jan. 2016.

40. A. Ghazanfari and Y. A.-R. I. Mohamed, "Decentralized Cooperative Control for Smart DC Home with DC Fault Handling Capability," IEEE Transactions on Smart Grid, vol. 9, no. 5, pp. 1-1, 2017.

41. P. Fairley, "DC Versus AC: The Second War of Currents Has Already Begun [In My View]," IEEE Power and Energy Magazine, vol. 10, no. 6, pp. 104-103, Nov. 2012. 